\title{
"WHAT YE DIVIN'T KNAA ABOOT THE CANNY LADS AND LASSES BACK YEM": A STUDY OF LANGUAGE AND IDENTITY IN THE GEORDIE VARIETY OF ENGLISH
}

\author{
Joaquín Bueno Amaro \\ University of Jaén (Spain)
}

\begin{abstract}
This paper concerns the close relation between language and identity and, more specifically, provides insights into the effects of the Geordie variety of the North East of England on its speakers. Dialectal studies are thus broadened to fields of society, community and identity. The pivotal points of this research are: 1) a detailed analysis of the linguistic characteristics of Geordie, not only phonetic-phonological, but also lexical and grammatical; 2) the reflection about the survey that has been conducted on Geordie identity for this paper; and 3) the combination of all these investigations in order to get a better understanding of the reasons behind the existence, maintenance and rejection of Geordie, as well as the bonds between the variety and the local community.
\end{abstract}

Keywords: sociolinguistics, phonetics, phonology, Geordie, dialect, British English.

\section{Resumen}

El trabajo versa sobre la estrecha relación idioma-identidad y, más específicamente, indaga en el efecto que tiene la variedad Geordie del inglés del noreste de Inglaterra en sus hablantes, ampliando así el estudio dialectal a un ámbito social, comunitario y de identidad. Los puntos principales de esta investigación son: 1) un análisis detallado de las características lingüísticas del Geordie, tanto fonético-fonológicas como léxicas y gramaticales; 2) un estudio de la encuesta que se ha llevado a cabo sobre la identidad Geordie para el presente trabajo; y 3) la combinación de los resultados de estos tres puntos para entender el porqué de la existencia del Geordie, el porqué de su mantenimiento y el porqué de su rechazo en otras regiones del país, así como lo que supone la variedad para la comunidad.

Palabras clave: sociolingüística, fonética, fonología, Geordie, dialecto, inglés británico 


\section{Introduction}

This paper is aimed at providing academic insights into the binominal language-identity in the case of the Geordie variety of English. The title has been planned to grab the attention of the reader and ignite their curiosity on the topic. "What ye divin't knaa aboot the canny lads and lasses back yem", spelt following Geordie conventions and worded with local vocabulary, means "What you don't know about the nice men and women back home."

The methodology is based on academic research relevant to the topic in hand, both from sources internal and external to the region under study, and on the results of a survey on Geordie identity which has been running for approximately three months, whose methodological aspects we shall detail further on due course.

The distinction between what can be considered a language and what can be considered a dialect is greatly controversial, to the point that a language was defined by Max Weinreich as "a dialect with an army and navy" (cf. Kaye 124). This is due to the unjust social evaluation of one of the terms being somewhat superior to the other. As Chambers and Trudgill (3) point out, dialects have for long been erroneously deemed as "a substandard, low-status, often rustic form of language, generally associated with the peasantry, the working class, or other groups lacking in prestige", and sometimes even aberrations or corrupted forms of the standard forms of a language. This attitude is slowly disappearing nowadays but it is still present, as this paper shall prove. Given the possible misinterpretations of the concepts of 'dialect' and 'accent', the more neutral term 'variety' is used all throughout the paper. We will often refer to the standard varieties of English: Standard British English (SBE) and Received Pronunciation (RP).

\section{The Geordie variety: Linguistic description}

The Geordie variety of English is spoken in the northernmost conurbation of England, the city of Newcastle-upon-Tyne and neighbouring towns. The region is also called Tyneside, which would include the city of Newcastle along with towns along the valley of the River Tyne as far as the North Sea (cf. Watt and Allen 267).

Geordie is an urban mode of speech considerably distinct from other England varieties in phonetic and phonological terms, and actually more similar to Scottish accents. It is wrongly thought that Scots spread south and originated Geordie, but the situation was actually the other way round: Scots is an 18thcentury version of the language spoken by settlers from Tyneside (cf. Moffat and Rosie 383).

If there is something that characterises Geordies, that is their pronunciation. Sharing many features with other English varieties from the Midlands northwards, Geordie also has exclusive phonetic-phonological features of its 
own. The ones listed below are the most salient, although, quite understandably, not every Geordie speaker will have all of them. The following list is a compilation of the features described in academic literature by Cruttenden (89), McArthur (75-77), Collins and Mees (142-154), Watt and Allen (267-271), Millward and Hayes $(375,376)$ and, to a minor extent, Wales (160-199).

- No h-dropping: the Geordie dialect is the only urban dialect which preserves the pronunciation of $/ \mathrm{h} /$.

- Non-rhoticity: Geordie is a non-rhotic accent, which means that $[\mathrm{x}]$ is not realised in post-vocalic positions, as in four or heart, unless followed by a vowel, as in very or parade. The intrusive [I] to mark word boundaries is not common either, and in such cases, Tyneside English is characterised by an intrusive glottal stop [?].

- Glottalisation of medial voiceless plosives: this might probably be one of the most distinguishing traits of Geordie speech. Intervocalic voiceless plosives, that is, $/ \mathrm{p} / / \mathrm{t} /$ and $/ \mathrm{k} /$, are replaced by a glottal stop [?] (for example: couple ['kuPəl], city ['sI?i:], better ['be?a], water ['wo:?a], reckon ['re?ən]). In some cases, it also happens with voiceless plosives between a sonorant and a vowel (for example: Ashington ['æ $\int \mathrm{I} \mathrm{I}$ ?ən] $)$.

- Preservation of Middle English (ME) /u:/, instead of RP /au/ (for example: about, also spelt aboot [ə’bu:t]; town, also spelt toon [tu:n]; down, also spelt doon [du:n]), and sometimes change into [iə] (for example: boot $[\mathrm{biət}])$.

- Preservation of ME /u/, instead of RP / $/$ / (for example: homophones put and putt [put], could and cud [kud], book and buck [buk], shook and shuck [Juk]): This is a major identifying feature of Geordie, and even most Northern Englishes.

- $\quad$ Long vowel /i:/ when followed by a former fricative sound, instead of $\mathrm{RP} / \mathrm{aI} / \mathrm{ME} / \mathrm{I} /$ when followed by a fricative lost the fricative and lengthened, but it did not diphthongise into /aI/ as it happened in RP (for example: fight [fi:t]; night, also spelt neet [ni:t]; right, also spelt reet as in alreet for all right [ri:t]).

- Open vowel similar to /a/ in final position or in centring diphthongs /ı/ and /ひə/, instead of RP /ə/ (for example: better ['be?a], beer [bia], cure ['kju:a]).

- Semi-open vowel /æ/ when followed by a voiceless fricative or by a nasal and a consonant, instead of RP /a:/ (for example: glass, path, France, past, laugh, homophones ant and aunt), as in General American.

- Long vowel /a:/ when followed by velar /1/ or /r/, instead of RP / /:/ and /əo/ (for example: all, also spelt al or aal [a:1]; talk [ta:k]; war [wa:]; cold [ka:ld]) 
- $\quad$ Long vowels /e:/ and /o:/, instead of RP diphthongs /eI/ and /ov/ (for example: face [fe:s], goat [go:t], away [ə’we:], snow [sno:], make [me:k]).

- Narrow diphthong [EI], instead of RP /aI/ (for example: Tyneside

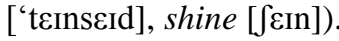

Regarding prosody, that is, intonation, pitch, voice quality, stress, loudness and rate of delivery, Tyneside and Geordie English are renowned for an extended lilting intonation with several final rising patterns, the so-called Geordie 'sing-song' which sounds to non-Geordies as tentative or questioning (cf. McArthur 76; Collins and Mees 154).

Dialectal vocabulary involves great part of a variety's distinctiveness. In contrast with the situation of other dialects, Geordie vocabulary is present in current and natural usage. The two main sources of Geordie vocabulary are Old English and Scandinavian languages.

Geordies and Scots share a great amount of dialect words due to the common heritage left by the Angles. For instance, the Geordie verb larn meaning 'to teach' is often misinterpreted as a wrong use of SBE learn; but it is in fact a modern reflex of the Anglo-Saxon verb laran, which meant 'to teach' compare Modern German lehren- (cf. British Library website). Some examples of shared vocabulary between Geordie and Scots coming from the Angles are: gan ('go'), bairn ('child'), bonny ('fine, good-looking'), canny (which in SBE means 'steady and cautious', but in Geordie means 'good, kind, gentle' and is even used as an intensifier meaning 'very'), yem ('home') and yon (demonstrative meaning 'that over there') (cf. McArthur 76; Collins and Mees 153; Moffat and Rosie 383; British Library website).

The influence of the Scandinavian languages on English is crucial, but even more so in the North, where there is a legion of borrowings, still surviving especially in rural areas. For example, fell ('hillside'), laithe ('barn'), garth ('yard'), laik/lake ('play'), brant ('steep'), steg ('gander'), by ('farmstead'), bait ('food'), aye ('yes') and nay ('no') (cf. Wales 55). Nonetheless, Old Norse had a more pervasive influence in Wearside, Teesside and County Durham than in Tyneside, where Anglian forms were preferred (for example: Durham and Teesside beck meaning 'stream', vs. Tyneside burn) (cf. Corrigan et al.).

Common Geordie forms of address include lad and man for men, and lass, hinny and pet for women. The expressions howay and haddaway, meaning respectively 'come on, hurry up' and 'go away', are very common and often used in everyday conversation. Another very frequent expression is wey aye followed by one of the terms of endearment mentioned above, meaning 'certainly, of course' or even only as a greeting. $\mathrm{Ta} t a$, also spelt $t a \mathrm{da}$ or taa taa, is commonly used for 'goodbye'. Frequent Geordie discourse fillers are like, profusely used in final position with no semantic function at all, why, used Figure 2in initial position as a substitute for SBE well, and you know. 
Last but not least, we should speak about Geordie personal pronouns. The dialectal forms are: $A a$ for first person singular subject ('I'), $u s$ or $i z$ for first person singular object ('me'), ye for second person singular subject and object ('you'), we for first person plural object ('us'), youse for second person plural subject and object ('you'), and the reflexive emphatic pronouns mysell, yoursell or yersell, hissell, hersell and worsells. The first person singular Aa resembles the $A h$ of Scots. The use of $u s$ for first person singular object may cause confusion to non-Geordies unaware of this feature, for they might think the speaker refers to a plural object. In order to avoid this confusion, Geordies do not use $u s$ for the plural object, but we. In fast speech, us or $i z$ usually merges with the previous word, resulting in phrases like Giz a call, meaning 'Give me a call'. The usage of youse is widespread among many other Northern varieties, most probably due to the influence of Hiberno-English -the one of Irish immigrants-. Here we should also mention the use of object pronouns as emphatic tags at the end of the utterance, a trait common in much of the North of England (I've always had casual work, me, you know), which vaguely reminds the reader of French emphatic pronouns, as in Je ne sais pas, moi.

\section{The Geordie identity: the survey}

This section will analyse the results drawn from the online survey on the Geordie identity run for this research. The survey accepted responses for almost 3 complete months, the first response being submitted on 11th March 2015 and the last one on 25th May. It gathered the helpful amount of 305 responses.

The 305 informants belonged to different gender, age and language groups. There were 203 women $(66.5 \%)$ and 102 men $(33.5 \%)$, and they were divided into four age-groups: $18-24,25-34,35-44$ and $45+$. The third classification is decisive with regard to the results of the survey. We asked the informants to choose the group to which they belonged: A) Native speaker of English and speaker of the Geordie variety $(113,37 \%)$; B) Native speaker of Non-Geordie English with some contact with Geordie speakers (90, 29.5\%); C) Native speaker of Non-Geordie English without any contact with Geordie speakers (19, $6.2 \%$ ); and D) Non-native speaker of English with some contact with Geordie speakers $(83,27.3 \%)$. We found it useful to gather the opinions both of Geordies and non-Geordies, as well as British and non-British. By the same token, it was important to distinguish between British informants who had had contact with Geordies (group B) and those who had not (group C).

The survey consisted of 35 questions, organised into four different sets. The first set, compulsory for all respondents, included 3 questions related to personal information about the informants. The next three sets tackled issues to do with identity, stereotypes, impressions, rejection and acceptance. Within this, the second set, marked by the letter A next to the question number, contained 9 questions exclusively aimed at Geordie speakers, and was compulsory for this group. The third set, marked by the letter B next to the question number, had 7 questions focused on the opinions of non-Geordies, and was compulsory for 
them. The fourth set was composed of the remaining 19 questions, aimed at both Geordies and non-Geordies. The questions of this fourth set were mandatory for all submitters, with the exception of four culture-related questions at the end.

The following is an analysis of the results from the questions that have been considered pivotal and more interesting to the research.

The first four questions in the Geordie-specific set (1A, 2A, 3A and 4A) concerned the frequency with which Geordie respondents had felt as being treated unfairly because of their accent. As we can see in figure 1, results are quite clear and revealing: around 95 respondents have rarely felt that they have received unfair treatment from authorities, educational institutions and in job situations; which is good news. Conversely, answers are not so outright regarding general prejudices in society: 10 people have felt often discriminated due to their accent, 39 sometimes, and 61 rarely.

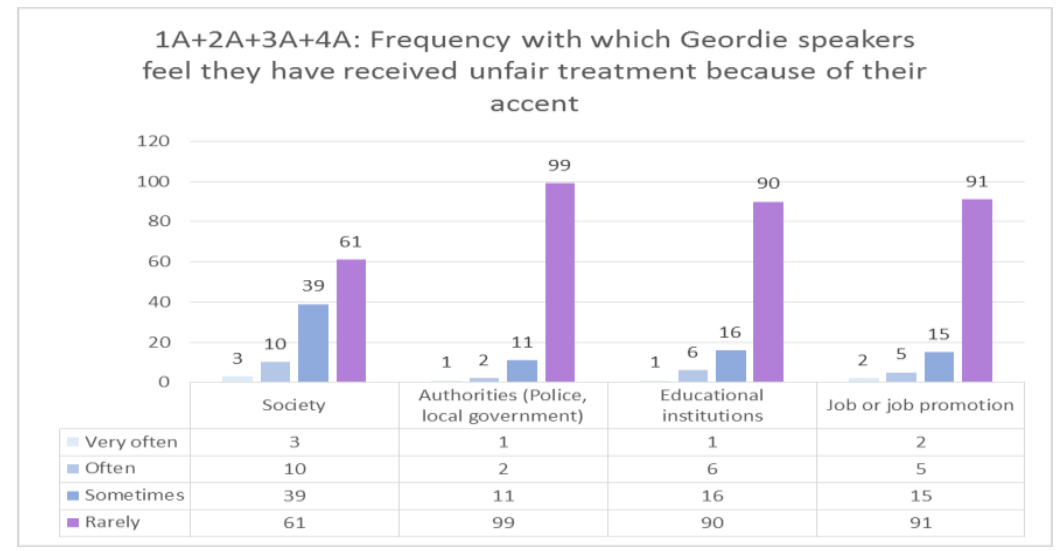

Figure 1

Figure 2 shows the combination of Geordies' answers to questions 9 (from

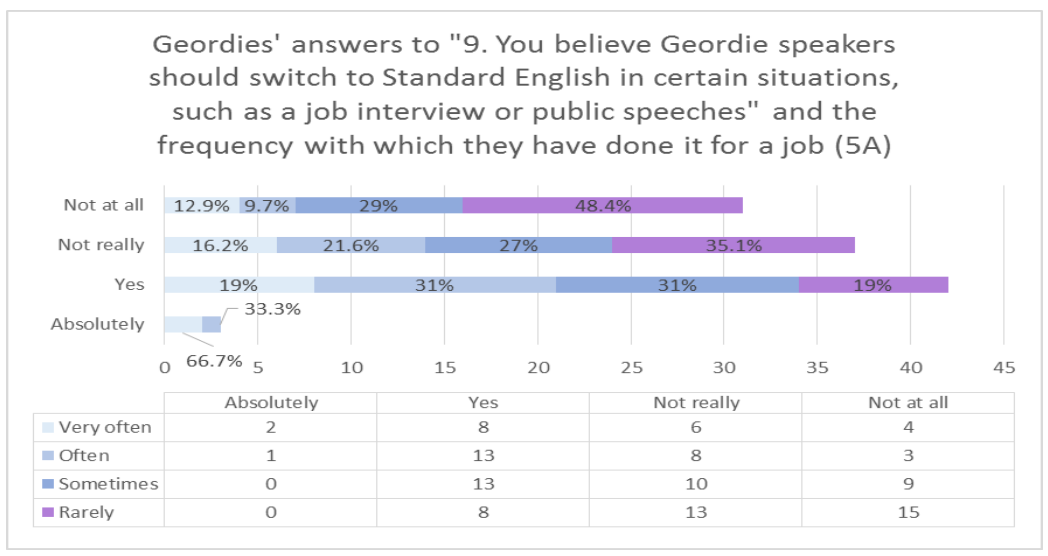

Figure 2 
the set answered by all submitters) and 5A (specific to Geordies). The former question surveyed on whether these speakers believed that they should switch to Standard British English in public situations, such as a job interview or public speeches; and the latter, on the frequency with which they have done so for a job.

Geordies who believed that it is essential or at least useful to switch to Standard British English in a job interview ('Absolutely' and 'Yes') unsurprisingly contribute to high percentages of 'Very often', 'Often' and 'Sometimes' in question 5A. The interesting fact arises from the answers of those who think that they should not switch to the standard variety at all in such situations ('Not at all'). Regardless of such opinion, $12.9 \%$ of them have done it very often; $9.7 \%$, often; and $29 \%$, sometimes. These results could prove that despite their personal opinions, these speakers are aware of the differences in prestige in a job interview between SBE and Geordie, and more than a half of them use SBE accordingly.

The other two questions in which we are especially interested from the Geordie-specific set are 7A and 8A, which poll Geordies on the influence the linguistic variety has on their identities. The first worth-mentioning result in Figure 3 is the fact that more than a half of all Geordie respondents believe this influence is very important. The second result that catches our attention is the absence of answers appealing to a very negative influence; and only 5 submitters out of 113 believe that it is negative. Conversely, a solid group of 89 respondents value it as 'Positive' or 'Very positive'.

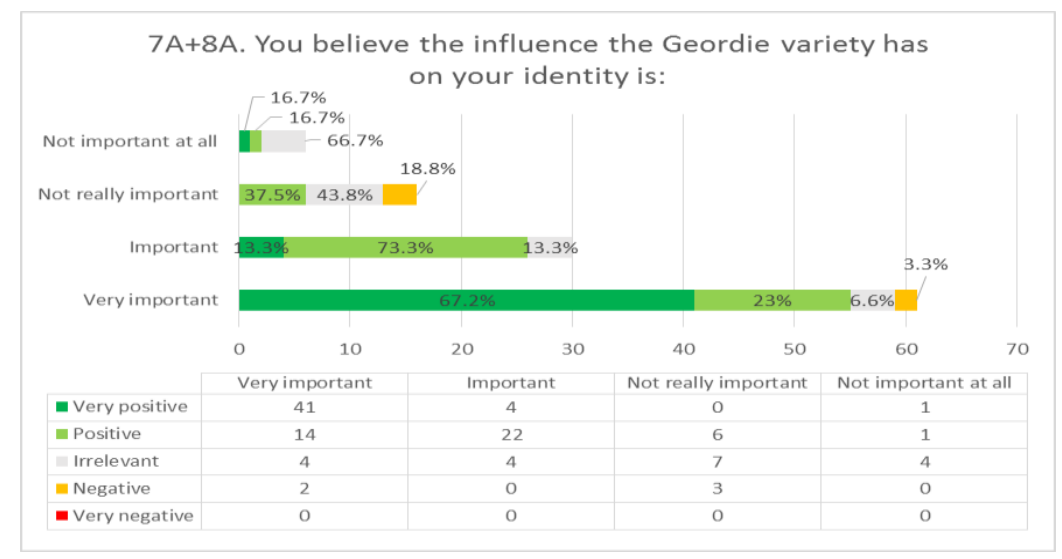

Figure 3

We move now to the second set of questions, only responded by nonGeordies. Here we will first focus our attention on question 1B (Figure 4), in which non-Geordies were asked to choose a maximum of two adjectives from a list of six to describe how the variety sounded to them. More than three quarters 
of the respondents opted for positive adjectives. 14\%, however, attached negative impressions to the variety.

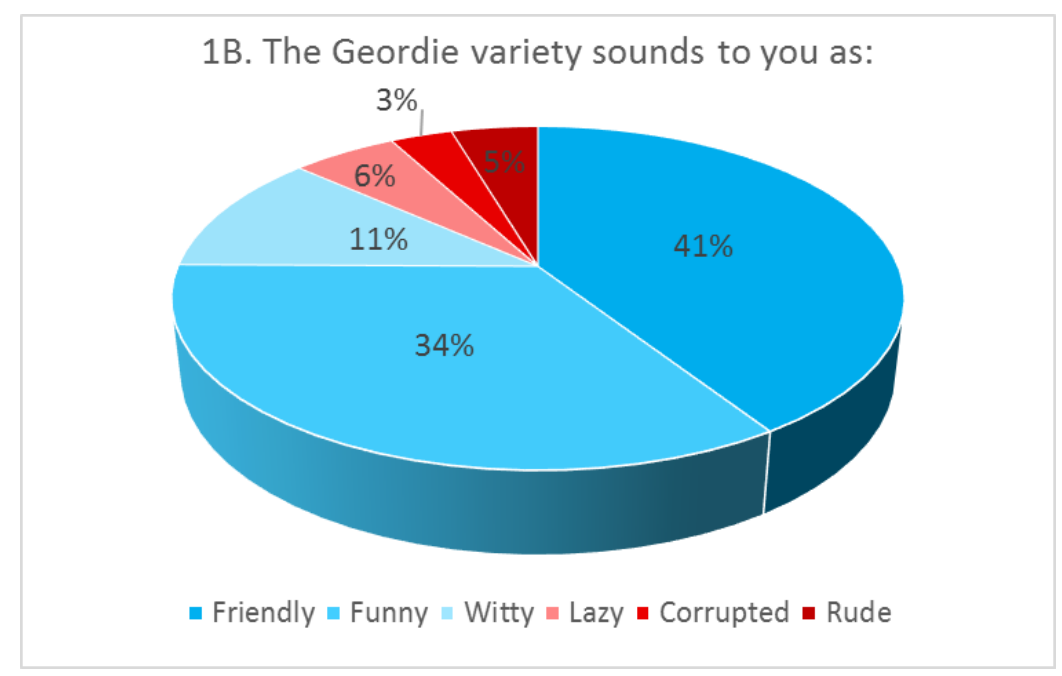

Figure 4

The following chart (figure 5) summarises the results obtained from questions $3 \mathrm{~B}$ and $4 \mathrm{~B}$, which value the frequency with which non-Geordies have been attracted to or put off from socialising with a Geordie speaker because of their accent. We found it useful here to arrange answers by groups B, C, and D.

Observing the results of the situations in which informants have been put off from socialising with a Geordie speaker because of their accent, we can see that this situation is not frequent, for the percentages of 'Rarely' are way over the other options in every group. Foreigners who have met Geordie speakers (group D) are in this case the group with the highest percentage of 'Sometimes' and 'Often' answers.

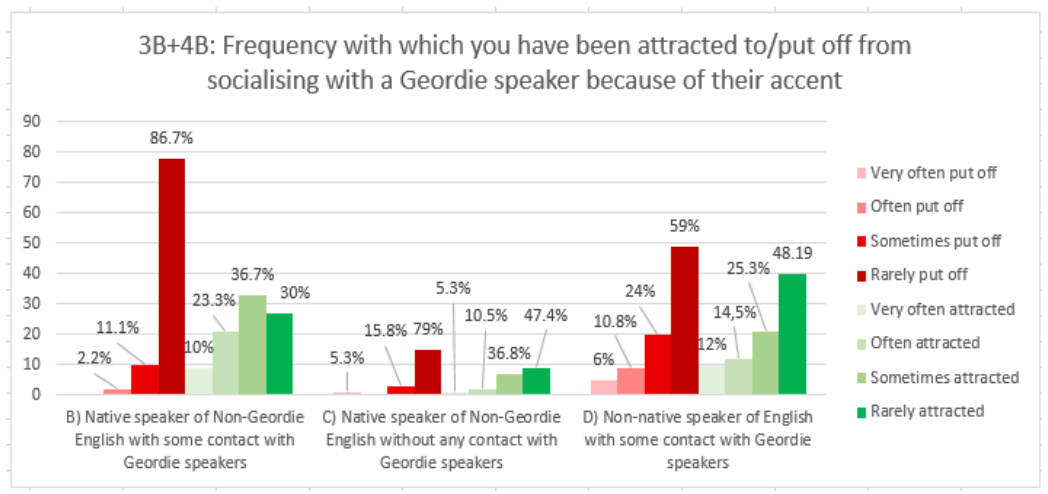

Figure 5 
And 'Often' answers. The reason for this could be that for a non-native speaker of English, Geordie pronunciation sounds very unfamiliar and probably difficult to understand; so they would rather avoid speaking to them.

Regarding the frequency with which the Geordie accent has attracted the informants to socialising with Geordies, almost half of group D opted for 'Rarely'. The Geordie accent has sometimes attracted around $37 \%$ of the British surveyees from groups B and C. We could deduce from these responses that the Geordie accent does not have a greatly relevant influence, either negative or positive, on the reasons why these informants would approach or not Geordie speakers.

The next set of questions is answered by all submitters, as we explained earlier, and means the core of the survey.

Figure 6 shows one of the most revealing results of the survey: almost half of the whole group of polled people believed that Geordie speakers receive unfair treatment due to their accent at least sometimes. Only a quarter of the surveyees opted for 'Rarely'. 18\% of the 305 submitters believe this happens often, and $9 \%$ very often. These results are quite thought-provoking, as they prove that the Geordie accent negatively conditions the way Geordies are treated in society. Thus, negative social implications of the Geordie pronunciation are proved true.

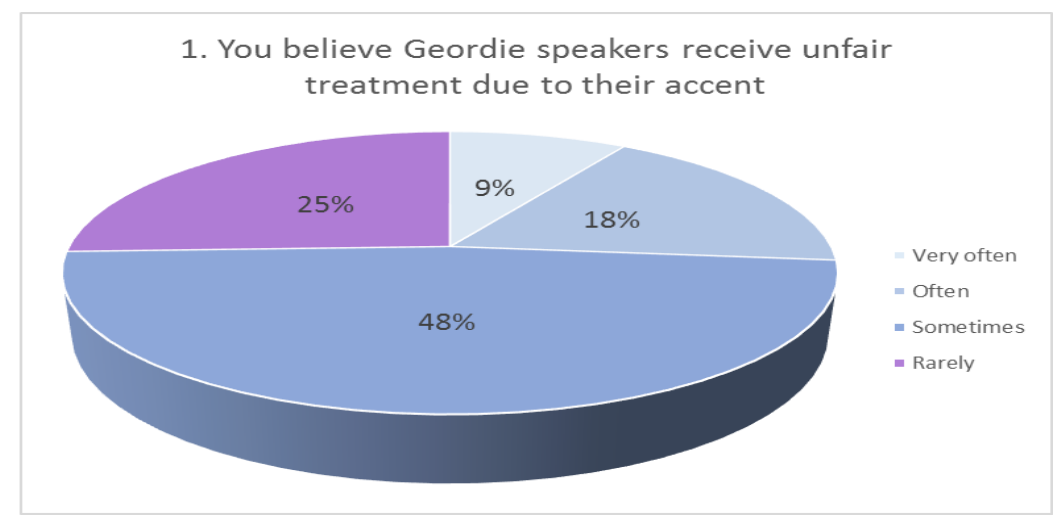

Figure 6

In the next chart (figure 7), all respondents take part in evaluating the influence of the variety on the city of Newcastle-upon-Tyne. As in the previous graph, both the importance and the positivity of such influence are tested. The first conclusion is that Geordie has a massive influence on the city. This idea is supported by the fact that only 1 out of the 305 believed that the influence was not important at all, and that a roaring $92 \%$ of the group believed it is important or very important. The second conclusion is that this influence affects the city positively. To prove this, it is enough to observe that only 2 out of 305 thought it was very negative compared to the 251 that believed it is positive or very positive. The third conclusion is that the overwhelming majority of people who 
deemed the Geordie variety important or very important for the city tilted towards the 'Very positive' and 'Positive' options. Other options for such respondents comprise less than $10 \%$ of the responses. Generally speaking, figures of 'Irrelevant' and 'Negative' in this chart are so scarce that they have no statistical relevance.

The next five questions we are going to analyse concern the role of different institutions (question 15), people (questions 16, 17 and 18) and events (question 19) in the public portrayal of Geordie speakers. The last four speak about culture-specific items, and that is the reason why they were set as optional. It was unadvisable for surveyees who did not know about such items to choose random options that could interfere in the correct reading of the results.

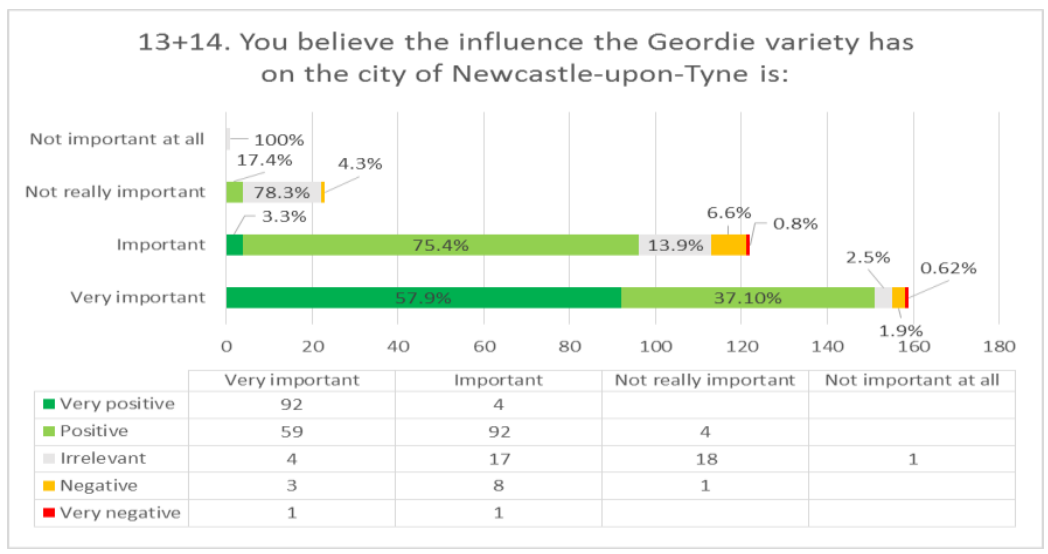

Figure 7

The results of 15 and 16 shall be commented together, for they are closely related and provide an interesting contrast of responses. Respondents were asked to choose a maximum of two options out of four to complete a statement in each question. The statement in 15 was 'You believe that, generally, the press, the TV, the radio and the Internet...' and in 16, 'You believe famous Geordie comedians such as Sarah Millican and Ant and Dec...'. Options were the same for both questions: two of them contributed to a better public portrayal of Geordies, and the other two to a less favourable or biased one. Pies in figures 8 and 9 are quite self-explanatory. While less than a quarter of the informants believed that means of communication help towards a good image of Geordies, almost three quarters believed so regarding famous Geordie comedians. It would also be flattering for those comedians to know that virtually half of the surveyed group believed that they aid towards a better social understanding of their fellow Novocastrians and their variety. Not surprisingly, however, $32 \%$ of the respondents think that Geordie comedians contribute to the use of the Geordie variety strictly for humorous purposes. The predominant red shades of figure 8 reveal that a sheer amount of informants consider that the press, the TV, the 
radio and the Internet have no positive influence whatsoever in the public image of Geordie speakers.

Questions 17 and 18 make reference to the influence of football-related people on the public representation of Geordies. The first of these questions polled the informants on whether they believed that Sir Bobby Robson and footballers such as Alan Shearer had given Newcastle and Geordie speakers a good reputation. There is an $85 \%$-strong opinion that the emblematic coach and the once captain of the national team of England have fostered a good reputation of the city and its people. Question 18 inquired about the role of the Toon Army, that is, the well-known group of football supporters of Newcastle United Football Club, in the good reputation of Newcastle and the Geordies. Nearly half of the respondents believed that the Toon Army has been beneficial, most probably as a symbol of community, union, and support. Still, the percentages of 'Not really' (40\%) and 'Not at all' (13\%) add up to a greater figure.

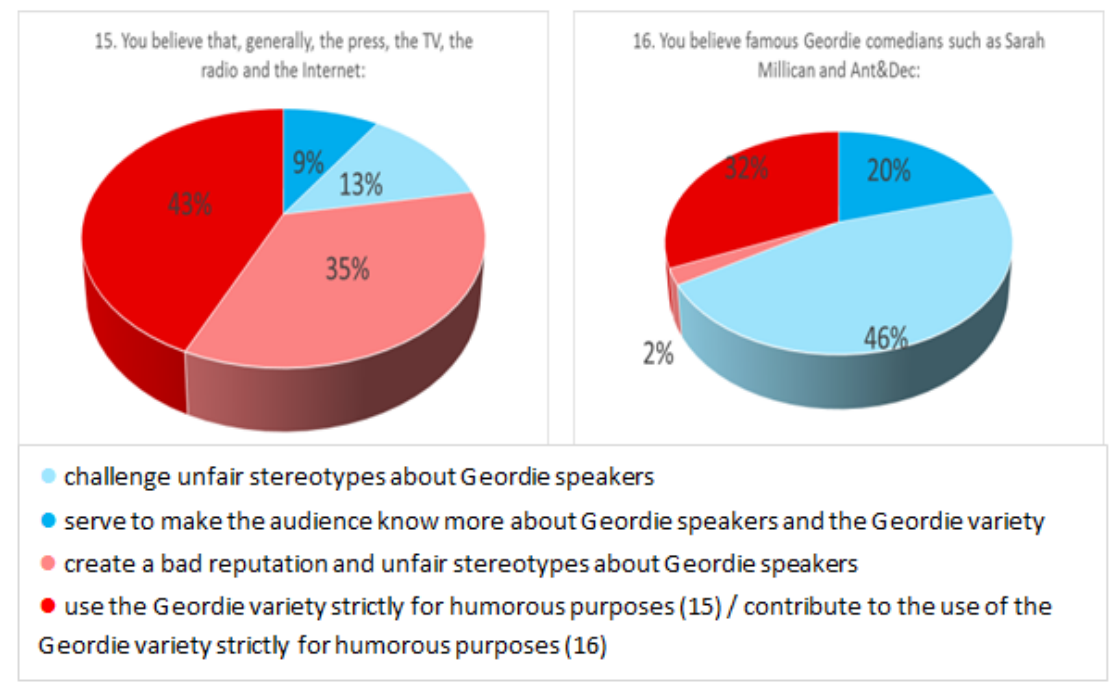

Figures 8 (left) and 9 (right)

The last chart (figure 10) concerns question 19: 'You believe the conflict between the miners and the Prime Minister Margaret Thatcher has given Newcastle and Geordie speakers a bad reputation'. This event, considered a turning point in the history of Newcastle and the area, took place in the last 20 years of the 20th century. The current temporal distance from the conflict required filtering responses by age groups. Here we should take into account percentages of each response within each age group rather than figures or bar height, for there was a great difference in the number of informants who answered the question for each age group: 97 in group 1, 54 in group 2, only 20 in group 3, and 89 in group 4. 


\begin{abstract}
19. You believe the conflict between the miners and the Prime Minister Margaret Thatcher has given Newcastle and Geordie speakers a bad reputation (filtered by age groups)
\end{abstract}

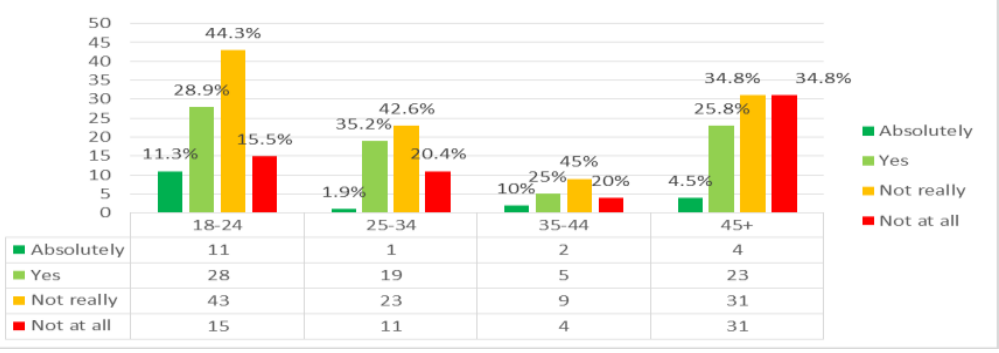

Figure 10

Only 45+ informants witnessed the conflicts, as they were at least in their teen years. The first three age groups had not been born by the time they took place. However, these informants, especially from the 25-34 and 35-44 groups, may have felt the aftermath effects of such disagreements. The highest percentage of 'Absolutely' answers comes from the youngest submitters, whereas the highest percentage of 'Not at all' comes from the oldest submitters. The groups in the middle have a greater amount of affirmative answers than the 45+ group, and more negative answers than the 18-24 group. Therefore, we could postulate that there is a gradual increase of the thought that these events scarred the public image of Newcastle and its people inversely proportional to the age increase; and the other way round: the older the respondents, the less they think the conflicts smeared Geordies' and Geordieland's reputation. These results are definitely food for thought. Nevertheless, the majoritarian answer in all age groups has been 'Not really', which suggests the following: most respondents believe that although the conflicts were not highly prejudicial reputationwise, they did not go unnoticed either -otherwise, they would have chosen 'Not at all'-.

\title{
4. Geordie identity and its links with the Geordie variety
}

This section will firstly analyse some aspects about the relation between Standard British English and Geordie and secondly give a chronological account of the way the Geordie identity has been forged and its current status.

In the 17th century, SBE started to gain status as the 'correct English' at the same rate as other social dialects started to be stigmatised. Although SBE was planned as a national language used indistinctly by all social classes, it did not take long in becoming a class dialect attached to the capitalist tier. At the other end, social dialects started to be regarded as vulgar, low and barbarous, and attached to working classes and uneducated lifestyles. McArthur (49) 
comments that these distinctions might have started to emerge in 1476, with the arrival of the printing press thanks to William Caxton, which gave a boost to the already influential language variety of the capital.

Being the main variety used in press, media, and culture, SBE has become "a passport to good jobs and positions of influence and power" (Fairclough 58). Generally, speakers acknowledge the dominance of the standard, as we could see from the survey results. However, that does not necessarily mean that they would always use it. Actually, "it [often] meets stiff resistance from speakers of other social dialects" (ibid.), such as the tight-knitted community of Geordie speakers. Here we should mention Trousdale's (19) concept of speech community, which groups together speakers who conventionally agree on the approppriate norms of language usage. In the case of Geordies, they belong to the ulterior speech community of British English speakers, but also to the powerful regional speech community of Geordie speakers. They would use one variety or the other depending on the situation, a phenomenon called diglossia in linguistic studies (cf. Kaye 127). We could wonder: why would they still use a non-standard variety that is often stigmatised instead of SBE?

Dialects are matchless tools to convey the sense of shared membership, the boundaries of our cultural and social regions, and the strong bonds we keep with those who speak the same (cf. Wales 205; Green and Pollard 16-17; Falck et al. 3; Trousdale 22). People need to feel as belonging to a group, to a region, and the use of a regional variety often becomes a marker of such membership that they are not willing to give up. Trousdale (26) highlights that this tends to happen in "strong (that is, dense and multiplex) networks, which are more resistant to the pressure to use Standard English." The Geordie network is one of them.

Regions comprise many intertwining aspects. Consequently, the signalling of an individual as member of a given region due to the variety s/he speaks unavoidably entails the identification of such individual with the lifestyles, clothing, and conduct stereotypically attached to the region. For instance, the survey proved that the Geordie variety not only marked someone as a person from Newcastle, but also as someone funny, witty, or even rude. Other questions proved that the media does not help much in changing those stereotypes.

The North started to be built up from very early ages as alien, barbarous, uncivilised, and even wild (cf. Wales 26). Colley (372, cited by Green and Pollard 8) mentions the 18th century as a period in which many regional identities merged into the British national identity, but many others, viz. the Northern identities, remained distinct. The rise of the middle class in the following century, together with the promulgation of education, helped towards dialect levelling and standardisation. However, it was in this same century, Wales (116-117) argues, that the growing industrial nature of northern regions such as Tyneside, their huge working class and their socio-economic homogeinity led to dialectal stability and conservatism. The Industrial 
Revolution intensified the medieval perceptions of a 'barbarous North' and contributed to the spread of urban dialects as well as to the loss of rural ones.

Victorian writers such as Dickens confirmed the images of harshness and dirt for the North, yet they were also kind in promoting "positive images of honesty, hard work and plain-speaking, which have continued to the present day" (Wales 123). Often disregarded, the North East and the North West produced a veritable treasure of local literature in the form of ballads, songs and music-hall, in the 18th and 19th centuries. Wales $(128-129,132-134,139)$ gives a detailed account of their influence on the Northern and Geordie identity. This vibrant local literature increased the self-awareness of local dialects and made use of them not only for communicative purposes, but also for deliberate performance and entertainment. In turn, creativity with the variety and local civic pride were given a reinforcement unheard-of in previous times. In subsequent centuries, this oral literature was put down into writing, which increased the interest of scholars in the dialects. Non-standard spellings, amongst other dialectal features, soon became an emblem of local identity, often associated with feelings and humour exclusive to the region. Such pride has clearly survived over the centuries and is present nowadays, as attested by our survey. Although informants acknowledged that Geordie speakers frequently received unfair treatment (question 1), results showed that Geordies majoritarily believed the influence of the variety on their identities is positive or very positive (questions 7A and 8A).

The local literature contained cultural archetypes that were kindly embraced by the community. In the case of Geordies, John Selkirk, in the first half of the 19th century, introduced the miner Bob Crankey, whose fame was later substituted by that of another archetype: 'Geordie', a name commonly given to miners and keelmen in these fictions. By the mid-19th century, the local literature made of the industrial worker an icon of the region and of 'Geordie' a new emblem affectionately and proudly used by the locals. When these Northern ballads travelled down south, actors did not have any problem in adapting their frames of social reference and dialect to be laughed at, rather than with. This had the risk of reinforcing metropolitan prejudices, but "self-parody is a characteristic feature of Northern popular culture generally" (Wales 139). Northern English became known more widely than ever before, and with the new forms of technological media, the image of 'Northern-ness' became so popular that 'being a northern' started to be in vogue. Modern-day comedians such as Sarah Millican and Ant and Dec account for the same situation nowadays. They not only portray the 'funny' side of Geordies, but also their cheekiness, warmth, and lack of pretension. Survey results prove that they are considered brilliant Geordie ambassadors.

During the second half of the 19th century, scholars in the fields of geography, anthropology and history began to pay special attention to regional histories and identities, threatened by modernisation (cf. Green and Pollard 16). However, the long-dreaded cultural uniformity to which modernisation was 
going to lead actually had the contrary effect: regional identities were reinforced, particularly in the industrial regions that were living their best days.

With the decline of the industrial world, many Northerners started to have part-time jobs related to culture, entertainment or teaching; and many went down south. These people experienced an intense boundary-crossing, where their solid regional identities often clashed with the powerful national identity down south. This process also involved the crossing of sociolinguistic and psycholinguistic boundaries in order to meet the norms of Standard British English. The situation brought about psychological tension, anxiety and friction, and a feeling of being in a social limbo, also termed 'liminality' (the state of being 'on the threshold' between clear social identities or 'between two worlds'). In the late 19th century and early 20th century, education received a governmental boost and it became a key stage for class mobility, especially for Northerners who were losing their jobs in the plummeting decline of their industries.

The relationship between language and class hardened and this was also the period in which SBE and especially RP were enjoying much more significance as elements for social mobility. This was favoured by factors such as the launch of the British Broadcasting Company in the 20's, which used RP as a nationally intelligible variety, and the reinforcement of the idea of the King's English in the figure of George V and the famous radio speech he gave in 1939, the first to be broadcast throughout the British Empire.

The Newbolt Committee, set up by the Board of Education in the 20's, fostered an aggressive educational program of dialect levelling against regional varieties. Such initiatives, focused not only on correcting pronunciation, but also grammar and lexis, followed ideas of social equality and of better employment, which in turn confirmed the image of dialects as quality-less sub-standard varieties. Consequently, young students fell again into the previously-discussed state of liminality, in-between the dialect they had learnt at home and the one they were being imposed at school. Many of these pupils started to experience a deep discomfort with the way they spoke, starting to believe that their dialectal traits were speech defects and social impediments, and they even understood and reinforced the stereotypes and stigmas that outsiders were building around them. Fortunately enough, the first survey questions we analysed show that in our time a hefty majority of Geordie speakers do not feel unfairly treated due to their accent in educational institutions.

Nonetheless, at almost the same rate as dialectal traits were being despised, they were also gaining an impressive prowess as markers of social and cultural identity. Here Wales (164) points at the post-War developments in cultural productions and media as encouraging "a greater acceptance nationally of regional variation in speech, while at the same time preserving Northern stereotypes to outsiders." Coronation Street, a soap opera set in the workingclass area of a fictional northern town, was first broadcast in 1960. Following the trend of the post-War realist fiction, it portrayed the lives of northerners 
striving for success. With an opening that presented a grim, smoky-looking neighbourhood, many were apprehensive about its success. Conversely, it is nowadays the longest running TV soap opera, and its characters have gained considerable popularity throughout the years, contributing to a kinder interest in the northern regions of the country. Just two years after Coronation Street began, came the Liverpudlian pop group The Beatles. Although they had little influence on the image of the Geordies, the Liverpool scene pushed to a resurgence of popular activity in Tyneside. "New television series like The Likely Lads (1964), When the Boat Comes In and later Auf Wiedersehen Pet (still popular in 2003-4) pushed Tyneside dialect and accent to the forefront of Northern English present and future national attention" (Wales 163). More than three quarter of our informants, however, think that the current image the media portrays of Geordies is often stereotypical and pigeonholed (question 15).

Hetherington comments that the North East and particularly Tyneside have been "endlessly parodied as [...] brown-ale-swilling [and] cloth-capped" and yoked with "the lilting, smooth-tongued, partying stereotype in a string of commercial voiceovers." Although elocution lessons may have disappeared, there are still speech therapists who earn their lives by helping northerners to get rid of their accents, and many still laugh at public figures with northern accents. 'Northern' and 'low-class' remain a strong collocation, and many popular films and series are to blame, say Brassed Off (1996), The Full Monty (1997), Billy Elliot (2000) or Geordie Shore (2011) (cf. Wales 167).

In contrast with these negative labels, there are also many positive stereotypes appealing to the Geordies' resilience, hard work, humour in the face of adversity, straight-forward opinions, friendliness and hospitality. In fact, these are often exploited in advertising to encourage selling, or in telephone sales and enquiries, for the way Geordies treat strangers is thought as kinder and more open. Question 1B of our survey supports this idea: an overwhelming majority of non-Geordies chose positive connotations over negative.

In the 21 st century, Newcastle has rebranded itself as Britain's party city, which has brought both positive income and negative stereotypes (boomed by TV series such as Geordie Shore). The city is nowadays teeming with university students and party-goers from all over the country. It offers a tempting range of party clubs, cafés, bars, restaurants and music halls, as well as expensive cruises across the Tyne and pleasure marinas in the river towns. Likewise, the transformation of historical industrial landmarks into museums and galleries, such as the use of the emblematic Baltic Flour Mills as the modern-art Baltic Museum on the banks of the Tyne, play a decisive in the promotion of local identity.

The city has also gained sporting status thanks to the rugby team Newcastle Falcons, but most importantly, thanks to Newcastle United Football Club. The football team, by climbing up in the Premier League, has succeeded in integrating the region again into the ensemble of the country. The survey has demonstrated that a vast number of Geordies feel deep local pride under its 
crest. The steadfast Toon Army can boast of being one of the most loyal football fandoms of Britain, and football celebrities like Alan Shearer and Sir Bobby Robson have contributed to such positive influence. Other notable locals that have made Geordies proud are the comedians Ant and Dec, and Sarah Millican; and the singers Sting and Cheryl Cole. "It cannot be stressed enough that a sense of a local identity, and pride therein, must help to preserve dialect; just as holding on to one's dialect contributes to the sense of local identity" (cf. Widdowson 10, cited by Wales 209).

The era of the Internet and social networks has modernised the means to assert dialectal and regional identities. In this respect, we should mention the many Facebook groups that have contributed to the survey. These groups gather Geordies of different ages, from different socio-economic backgrounds and even from different places around the globe -groups of Geordie expatriates-. Their wholehearted support to the research has proved right their famed openness and friendliness, which we have greatly appreciated.

Wales (211) remains "optimistic that, of all the varieties of English remaining within England at the beginning of this new millennium it is Northern English, especially its distinctive accents, that will survive the longest." Geordies can be considered a spirited community and adversities have done nothing but unite them further. The variety of English they speak has remained an identity marker of utmost importance.

\section{Conclusions}

We expect that this paper has given an informative account of the characteristics of the Geordie variety, of its status as a social tool and of its ties with the identity of the people from Newcastle-upon-Tyne. The combination of academic investigation, the survey, and my own personal experience should have provided enough evidence about the incontestable relation between the Geordie variety and the identity of its speakers.

The survey has proved many relevant facts. On the one side, its results have confirmed the Geordies' strong sense of local unity and pride, and the fact that outsiders recognise such feelings. On the other side, it has happily proved that the Geordie variety is little by little moving from negative to positive stereotypes, although there still exist many uncomfortable clichés.

Standard British English and Received Pronunciation cast a long shadow over the Geordie variety. Pressure coming from social mobility, education, and mainstreaming media threatens to suffocate the dialectal traits of Novocastrians. Besides, the Geordies are still castigated with die-hard myths and stereotypes. However, their powerful community sentiment is putting up a formidable fight so far, and will keep doing so for long. The concept of 'Geordie-ness' has reinvented itself over the centuries and would do it again if necessary. 


\section{WORKS CITED}

British Library. "Geordie: a regional dialect of English." Web. <http://www.bl.uk/learning/langlit/sounds/case-studies/geordie/> [Last accessed: 10th June 2015].

Chambers, Jack K., and Peter Trudgill. 1980. Dialectology. 2nd edition. Cambridge: Cambridge University Press, 1998.

Colley, Linda. Britons: Forging the Nation, 1707-1837. Newhaven, Connecticut: Yale University Press, 1992.

Collins, Beverley and Inger M. Mees. Practical Phonetics and Phonology: A Resource Book for Students. London: Routledge, 2003.

Corrigan, Karen P., Isabelle Buchstaller, Adam Mearns and Hermann Moisl. 2012. The Talk of the Toon. Newcastle University. Web. <http://research.ncl.ac.uk/decte/toon> [Last accessed: 11 th June 2015].

Cruttenden, Alan. Gimson's Pronunciation of English. London: Arnold, 2001.

Fairclough, Norman. Language and Power. London: Longman, 1989.

Falck, Oliver, Stephan Heblich, Alfred Lameli and Jens Südekum. "Dialects, cultural identity and economic exchange." Institut d'Economia de Barcelona Working Papers 26 (2010). Barcelona: Universitat de Barcelona.

Green, Adrian and Anthony J. Pollard (eds.). Regional Identities in North-East England, 1300-2000. Wooldridge: Boydell, 2007.

Hetherington, Peter. "Geordies look to saint for inspiration." The Guardian. Web. $16 \quad$ June 2003. <http://www.theguardian.com/uk/2003/jun/16/society.politics> [Last accessed: 12th June 2015].

Jenkins, Jennifer. World Englishes: A Resource Book for Students. London: Routledge, 2003.

Kaye, Alan S. 2001. "Diglossia: the state of the art." International Journal of the Sociology of Language 152: 117-129. Web. <http://www.international.ucla.edu/media/files/Kaye_diglossia.pdf> [Last accessed: 16th June 2015].

McArthur, Tom. Oxford Guide to World English. New York: Oxford University Press, 2002.

Millward, Celia M. and Mary Hayes. 1996. A Biography of the English Language. 3rd edition. Boston: Wadsworth, 2012.

Moffat, Alistair and George Rosie. Tyneside: A History of Newcastle and Gateshead from Earliest Times. Edinburgh; London: Mainstream Publishing, 2006.

Trousdale, Graeme. Introduction to English Sociolinguistics. Edinburgh: Edinburgh University Press, 2010.

Wales, Katie. Northern English, a Cultural and Social History. Cambridge: Cambridge University Press, 2006. 
Watt, Dominic and William Allen. "Tyneside English." Journal of the International Phonetic Association 33 (2003): 267-271.

Widdowson, John D.A. "Sheffield dialect on the eve of the millennium." Transactions of the Yorkshire Dialect Society 99.19 (1999): 9-19.

Received: 30 October 2015 Accepted: 27 November 2015 